\title{
Clinical education and training: Have we sufficiently shifted our paradigm?
}

In 2010, almost a decade ago, Frenk et al. ${ }^{[1]}$ reported that health professions education needs to be transformed to appropriately address the health needs of the population in the 21 st century. The authors further suggested that a competency-based curriculum would facilitate this transformation process. ${ }^{[1]}$ The competencies that should be facilitated in such a curriculum should be aligned with the roles that health professionals need to fulfil to respond to the population's health needs. These above-mentioned roles include being a collaborator, manager, health advocate, good communicator, professional and scholar. ${ }^{[2]}$ It is therefore important that the clinical education and training component of health professions education programmes includes learning outcomes, teaching and learning activities, as well as assessment tasks that would facilitate the development of these competencies.

The articles in this edition of AJHPE report on a number of aspects related to clinical education and training. The papers provide insights into approaches and models of clinical education, as well as the different learning activities students engage in as they become competent practioners. The aspects of an integrated model of clinical education are explored by Chetty et al., ${ }^{[3]}$ while additional perspectives about interprofessional education and practice are provided by Moodley and Singh. ${ }^{[4]}$ Data relating to effectiveness and experiences of students acting as advocators of good health are reported on by Mhlongo et al. ${ }^{[5]}$ and Smit et al. ${ }^{[6]}$ The exploration of teaching and learning activities, such as telehealth ${ }^{[7]}$ and performance art, ${ }^{[8]}$ demonstrates that educators continue to examine different innovative methods to develop competencies of health professions students.

Using both qualitative and quantitative methodologies, the samples reported on in the published articles include a variety of professions, such as pharmacy, dentistry, physiotherapy and dietetics. The inclusion of studies related to interns by Naidoo et al. ${ }^{[9,10]}$ indicates that research in the field of health professions education extends beyond undergraduate programmes.

Even though the main objective of clinical education and training, which involves placing students on varied clinical platforms, is to develop specific clinical competencies in students, the positive impact of having students on a specific clinical platform is reported on by Reid et al. ${ }^{[11]}$ This is an important aspect to consider in settings where human resources for health are limited.

As we read the information shared with us in this edition of $A J H P E$ and reflect on initiatives implemented by health professions educators, such as interprofessional education and collaborative practice, ${ }^{[12]}$ we need to ask how far we have come with training students who can address the health needs of the population in the 21st century, and, moreover, if graduates are equipped with skills to address the existing healthcare disparities. ${ }^{[13]}$

If we are serious about the competencies needed by health professions graduates to meet the needs of communities in the 21st century, we need to continually review how we design and implement clinical education and training programmes. We might need to further shift our paradigms with regard to the manner in which we view clinical education and training. Information provided by articles in this edition of AJHPE could contribute to this paradigm shift.

\section{Anthea Rhoda}

Faculty of Community and Health Sciences,

University of the Western Cape, Cape Town, South Africa arhoda@uwc.ac.za

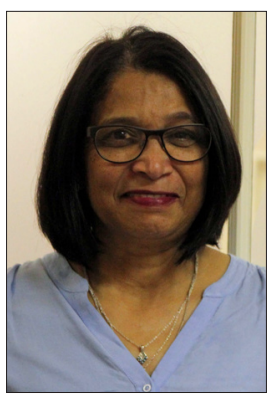

1. Frenk J, Chen L, Bhutta ZA, et al. Health professionals for a new century: Transforming education to strengthen health systems in an interdependent world. Lancet 2010;376(4):1958-1923. https://doi.org/10.1016/S01406736(10)61854-5

2. Frank JR, Snell L, Sherbino J, eds. CanMEDS 2015 Physician Competency Framework. Ottawa: Royal College of Physicians and Surgeons of Canada, 2015.

3. Chetty V, Maddocks S, Cobbing S, et al. Physiotherapy clinical education at a South African university. Afr J Health Professions Educ 2018;10(1):13-18. https://doi.org/10.7196/AJHPE.2018.v10i1.987

4. Moodley I, Singh S. Creating opportunities for interprofessional, community-based education for undergraduate dental students within the School of Health Sciences at the University of KwaZulu-Natal, Durban, South Africa: Academics' perspectives. Afr J Health Professions Educ 2018;10(1):19-25. https//:doi.org/10.7196/AJHPE.2018. v10i1.974

5. Mhlongo M, Marara P, Bradshaw K, Srinivas SC. Health education on diabetes at a South African national science festival. Afr J Health Professions Educ 2018;10(1):26-30. https://doi.org/10.7196/AJHPE.2018.v10i1.887

6. Smit Y, Marais M, Philips L, Donald H, Joubert E. Engagement of dietetic students and students with hearing loss: Experiences and perceptions of both groups. Afr J Health Professions Educ 2018;10(1):31-37. https://doi. org/10.7196/AJHPE.2018.v10i1.901

7. Govender SM, Mars M. The perspectives of South African academics within the disciplines of health sciences regarding telehealth and its potential inclusion in student training. Afr J Health Professions Educ 2018;10(1):3843. https://doi.org/10.7196/AJHPE.2018.v10i1.957

8. Schweickerdt L. Adopting a role: A performance art in the practice of medicine. Afr J Health Professions Educ 2018;10(1):3-4. https://doi.org/10.7196/AJHPE.2018.v10i1.950

9. Naidoo KL, van Wyk J, Adhikari M. Comparing international and South African work-based assessment of Naidoo KL, van Wyk J, Adhikari M. Comparing international and South African work-based assessment of
medical interns' practice. Afr J Health Professions Educ 2018;10(1):44-49. https://doi.org/10.7196/AJHPE.2018. v10i1.955

10. Naidoo KL, van Wyk J, Adhikari M. 'Sense of belonging': The influence of individual factors in the learning environment of South African interns. Afr J Health Professions Educ 2018;10(1):50-55. https://doi.org/10.7196 AJHPE.2018.v10i1.953

11. Reid S, Conradie H, Daniels-Felix D. The effect of undergraduate students on district health services deliver in the Western Cape Province, South Africa. Afr J Health Professions Educ 2018;10(1):56-60. https://doi org/10.7196/AJHPE.2018.v10i1.959

12. Frantz JM, Rhoda AJ. Implementing interprofessional education and practice: Lessons from a resourceconstrained university. J Interprof Care 2017;31(2):180-183. https://doi.org/10.1080/13561820.2016.1261097

13. Mayosi BM, Benatar SR. Health and health care in South Africa - 20 years after Mandela. N Engl J Med 2014;371:13441353. https://doi.org/10.1056/NEJMsr1405012

Afr J Health Professions Educ 2018;10(1):2. DOI:10.7196/AJHPE.2018.v10i1.1080 